\title{
Article \\ Hydrogen Permeation Behavior of Zirconium Nitride Film on Zirconium Hydride
}

\author{
Wenke Wang 1,2,3,4, Guoqing Yan 1,3,4 , Jiandong Zhang 1,3,4, Zhaohui Ma ${ }^{1,3,4}$, Lijun Wang 1,3,4,*, Zhancheng Guo ${ }^{2}$, \\ Shunli Zhang ${ }^{1,3,4}$ and Yanke $\mathrm{Wu}^{1,3,4}$ \\ 1 National Engineering Research Center for Environment-Friendly Metallurgy in Producing Premium \\ Non-Ferrous Metals, GRINM Group Corp. Ltd., Beijing 101407, China; wwk18801271070@163.com (W.W.); \\ 18500936007@163.com (G.Y.); zjd332@163.com (J.Z.); mazhaohui@grinm.com (Z.M.); \\ 18611123468@163.com (S.Z.); luckwyk@163.com (Y.W.) \\ 2 State Key Laboratory of Advanced Metallurgy, University of Science and Technology Beijing, \\ Beijing 100083, China; zcguo@ustb.edu.cn \\ 3 GRINM Resources and Environment Tech. Co. Ltd., Beijing 101407, China \\ 4 General Research Institute for Nonferrous Metal, Beijing 100088, China \\ * Correspondence: gold@grinm.com
}

Citation: Wang, W.; Yan, G.; Zhang, J.; Ma, Z.; Wang, L.; Guo, Z.; Zhang, S.; Wu, Y. Hydrogen Permeation Behavior of Zirconium Nitride Film on Zirconium Hydride. Materials 2022, 15, 550. https://doi.org/ $10.3390 / \mathrm{ma} 15020550$

Academic Editor: Haralampos N. Miras

Received: 6 December 2021

Accepted: 5 January 2022

Published: 12 January 2022

Publisher's Note: MDPI stays neutral with regard to jurisdictional claims in published maps and institutional affiliations.

Copyright: (C) 2022 by the authors. Licensee MDPI, Basel, Switzerland. This article is an open access article distributed under the terms and conditions of the Creative Commons Attribution (CC BY) license (https:// creativecommons.org/licenses/by/ $4.0 /)$.

\begin{abstract}
Hydrogen permeation barrier plays an important role in reducing hydrogen loss from zirconium hydride matrix when used as neutron moderator. Here, a composite nitride film was prepared on zirconium hydride by in situ reaction method in nitrogen atmosphere. The phase structure, morphology, element distribution, and valence states of the composite film were investigated by XRD, SEM, AES, and XPS analysis. It was found that the composite nitride film was continuous and dense with about $1.6 \mu \mathrm{m}$ thickness; the major phase of the film was $\mathrm{ZrN}$, with coexistence of $\mathrm{ZrO}_{2}, \mathrm{ZrO}$, and $\mathrm{ZrN}_{0.36} \mathrm{H}_{0.8}$; and $\mathrm{Zr}-\mathrm{C}, \mathrm{Zr}-\mathrm{O}, \mathrm{Zr}-\mathrm{N}, \mathrm{O}-\mathrm{H}$, and $\mathrm{N}-\mathrm{H}$ bonds were detected in the film. The existence of $\mathrm{ZrN}_{0.36} \mathrm{H}_{0.8}$ phase and the bonds of $\mathrm{O}-\mathrm{H}$ and $\mathrm{N}-\mathrm{H}$ revealed that the nitrogen and oxygen in the film could capture hydrogen from the zirconium hydride matrix. The hydrogen permeation performance of nitride film was compared with oxide film by permeation reduction factor (PRF), vacuum thermal dehydrogenation (VTD), and hydrogen permeation rate (HPR) methods, and the results showed that the hydrogen permeation barrier effects of nitride film were better than that of oxide film. The zirconium nitride film would be a potential candidate for hydrogen permeation barrier on the surface of zirconium hydride.
\end{abstract}

Keywords: zirconium hydride; zirconium nitride film; hydrogen permeation mechanism; hydrogen permeation rate; in-situ reaction; neutron moderator

\section{Introduction}

The type of reactor included gas cooled reactor (GCR), light water reactor (LWGR), heavy water reactors (PWR), and fast reactors (FRs) [1]. The space reactor included thermal neutron reactor and fast neutron reactor. There were Romaska, Topaz-I, Topaz-II and Topaz in Russia's research on space reactor, and the life of them were from Several months to 7 years. American research on space reactor included SNAP-10A and SNAP-100, and the life of them were 43 days and 7-10 years [2,3].

Because of its high thermal stability, high hydrogen density [4], low neutron capture cross-section, and good thermal conductivity [5-7], zirconium hydride became an ideal neutron moderator and was put into application in space nuclear reactor. However, hydrogen will escape from zirconium hydride in the working environment, leading to the loss of hydrogen and hence deteriorating the moderating effect of the moderator [8]. The hydrogen loss can be prohibited or hindered by manufacturing a hydrogen permeation barrier film on the surface of zirconium hydride. 
Substantial research has been conducted on the preparation of hydrogen permeation barrier on stainless steel, such as oxide films of $\mathrm{Y}_{2} \mathrm{O}_{3}, \mathrm{Cr}_{2} \mathrm{O}_{3}$, and $\mathrm{Al}_{2} \mathrm{O}_{3}$ [9-11], carbide films of $\mathrm{SiC}$ [12], and nitride films of $\mathrm{AlN}, \mathrm{Si}_{3} \mathrm{~N}_{4}, \mathrm{BN}$, TiAlN [13-17], and PRF values measured were from 40 to 20,000. Zirconium hydride was generally used in honeycomb structure, which made the preparation method of the hydrogen permeation barrier on stainless steel unsuitable for it. Therefore electroplating, micro arc oxidation, sol-gel, and in situ reaction methods were developed to form hydrogen permeation barrier on the zirconium hydride. Chen et al. [18] studied the preparation of the films on zirconium hydride by in situ reaction method in $\mathrm{O}_{2}, \mathrm{CO}_{2}$, and $\mathrm{CO}_{2}+\mathrm{P}$ atmospheres, and the results showed the $\mathrm{M}-\mathrm{ZrO}_{2}$ and $\mathrm{T}-\mathrm{ZrO}_{2}$ film structure, and the films prepared in $\mathrm{CO}_{2}+\mathrm{P}$ atmosphere had the best hydrogen blocking effect. Wu et al. $[19,20]$ prepared composite oxide films containing Si-Al, Si-Zr, and Si-P on the zirconium hydride by sol-gel method, obtaining a top sol-gel layer and a transition zirconium oxide bottom layer with excellent hydrogen barrier effect. Yan et al. [21] fabricated $\mathrm{ZrO}_{2}$ composite film by in situ reaction of urea with zirconium hydride at high temperature, resulting in a film composed of $\mathrm{Zr}, \mathrm{C}, \mathrm{N}$, and $\mathrm{O}$ elements; and $\mathrm{C}-\mathrm{H}, \mathrm{O}-\mathrm{H}$, and $\mathrm{N}-\mathrm{H}$ bonds were detected in the film, revealing that hydrogen was trapped by $\mathrm{C}, \mathrm{N}$, and $\mathrm{O}$ in the coating. Qi et al. [22] prepared phosphating film on zirconium hydride, for which the hydrogen permeation rate of samples was measured by gas chromatography, and the hydrogen loss predicted showed a good performance.

Nitride film has also been an important hydrogen barrier category because of its good hydrogen permeation barrier effect, high hardness, and excellent corrosion resistance $[23,24]$. Methods for preparing nitride film include ion nitriding, carbonitriding and gas nitriding, in which gas nitriding is divided into ammonia nitriding and nitrogen nitriding [24]. Zhang et al. [25] utilized ultrasonic nanocrystalline surface modification (UNSM) technology and low-temperature ammonia nitriding to prepare nitriding layer on the surface of NiCr 718 alloy where the grain boundaries on the surface of the nanocrystals provided the diffusion channels of nitrogen, and this technology reduced the nitriding temperature and time, and improved the hardness, wear resistance, and corrosion resistance of the nitride films. Yilbas et al. [26] prepared nitriding layers on the surface of the tungsten using high-pressure nitrogen with laser assistant, which made the surface of the tungsten nanocrystalline free of microcracks and large-size holes, and the surface hardness was significantly improved, and this nitriding process overcame the binding force of the metal atoms on the metal surface by producing active nitrogen atoms, thus penetrated into the matrix [24]. However, thus far, no research has been published on forming nitride film on zirconium hydride.

In this study, zirconium nitride film was prepared on zirconium hydride by nitrogen nitriding. The phase structure, morphology, element and valence distribution of the film were investigated. The hydrogen permeation performance of nitride film was studied, and was compared with oxide film manufactured by in situ reaction with $\mathrm{CO}_{2}$ [18]. The hydrogen permeation mechanism of the nitride film was revealed.

\section{Materials and Methods}

\subsection{Preparation of Hydrogen Permeation Barrier}

Zirconium hydride $(\mathrm{H} / \mathrm{Zr}=1.8)$ with the size of $\Phi 20 \mathrm{~mm} \times 3 \mathrm{~mm}$ was prepared by our own research group in National Engineering Research Center for Environment-friendly Metallurgy in Producing Premium Non-ferrous Metals (Beijing, China). Moreover, it was prepared by injecting hydrogen into zirconium niobium alloy, controlling temperature and pressure of the furnace, and zirconium hydride with a certain hydrogen content could be obtained. The purity of zirconium hydride was analyzed by inductive coupled plasma emission spectrometer (ICP), and the contents of $\mathrm{O}$ and $\mathrm{N}$ in the sample were analyzed by LECO ONH836 analyzer (St. Joseph, MO, USA). The results are shown in Table 1. The elements $\mathrm{Al}, \mathrm{B}, \mathrm{Cd}, \mathrm{Co}, \mathrm{Cr}, \mathrm{Cu}, \mathrm{Mg}, \mathrm{Mn}, \mathrm{Mo}, \mathrm{Ni}, \mathrm{Pb}, \mathrm{Si}, \mathrm{Sn}, \mathrm{Ti}, \mathrm{V}$ and W were all $<0.001 \%$. Before the experiment, zirconium hydride was polished to $6.5 \mu \mathrm{m}$ using a sandpaper step by step, and then cleaned ultrasonically in $99.7 \%$ ethanol for 
$300 \mathrm{~s}$. The power of YA008G ultrasonic cleaning machine (Shenzhen, China) was $80 \mathrm{~W}$. The polished zirconium hydride sample was sealed in quartz tube with 20,000 Pa nitrogen (the purity was 99.99\%); subsequently, the packaged quartz tube was placed in a tubular furnace, and the temperature of the furnace was raised from room temperature to $800{ }^{\circ} \mathrm{C}$ at $1{ }^{\circ} \mathrm{C} / \mathrm{min}$. After keeping for $20 \mathrm{~h}$, the furnace was cooled to room temperature, and the film was obtained.

Table 1. Contents of impurity elements in zirconium hydride.

\begin{tabular}{cccccc}
\hline Element & Fe & Hf & Nb & O & N \\
\hline Content $/ \omega t \%$ & 0.003 & 0.0052 & 0.96 & 0.0056 & 0.0043 \\
\hline
\end{tabular}

\subsection{Characterization of Composition, Morphology and Structure}

Scanning electron microscope (SEM, Hitachi S-4800, Tokyo, Japan) was employed to observe the surface and cross-section morphologies of the film. The energy dispersive X-ray spectrometer (EDS) equipped on the SEM was used to characterize the elements distribution of the film. X-ray diffraction (XRD, Smartlab KD2590N, Tokyo, Japan) was employed to investigate the phase of the surface layer. The composition and element distribution of the film was analyzed by Auger electron spectroscopy (AES, ULVAC PHI-700, Chigasaki, Japan). The chemical valence states of the film were analyzed by X-ray photoelectron spectroscopy (XPS, Thermo Scientific ${ }^{\mathrm{TM}} \mathrm{Nexsa}^{\mathrm{TM}}$, Waltham, MA, USA). The hydrogen content of the zirconium hydride before and after in situ reaction was determined by high-temperature dehydrogenation method.

Before the measurement, the samples were all cleaned ultrasonically in ethanol to remove contaminants. Particularly, the samples were measured by SEM to observe crosssection morphology by wire cutting, inlayed with resin, polished to $6.5 \mu \mathrm{m}$ with sandpaper step by step, and then cleaned ultrasonically in ethanol.

\subsection{Characterization of Hydrogen Permeation Behavior}

To study the hydrogen permeation behavior, the following three methods were employed: (1) permeation reduction factor (PRF) [11]; (2) vacuum thermal dehydrogenation (VTD) [20]; (3) hydrogen permeation rate (HPR) [22]. Hydrogen permeation behavior of nitride film samples prepared in nitrogen atmosphere at $800{ }^{\circ} \mathrm{C}$ was studied, and was compared with that of oxide film manufactured by in situ reaction with $\mathrm{CO}_{2}$ [18]. The samples investigated are listed in Table 2.

Table 2. Samples investigated for hydrogen permeation behavior.

\begin{tabular}{ccc}
\hline Sample & Film & Initial Thicknesses \\
\hline $\mathrm{ZrH}_{1.8}$ with nitride film & $\mathrm{ZrN}$ & $1.6 \mu \mathrm{m}$ \\
$\mathrm{ZrH}_{1.8}$ with oxide film & $\mathrm{ZrO}_{2}$ & $2 \mu \mathrm{m}$ \\
\hline
\end{tabular}

\subsubsection{Permeation Reduction Factor}

The PRF method was used to evaluate the hydrogen permeation resistance performance by mass loss. The samples with and without film were put into a vacuum furnace and kept at the same set temperature for the same set period of time. The mass loss of samples before and after the experiment was considered to evaluate the hydrogen loss. The definition of PRF was as follows:

$$
\mathrm{PRF}=\Delta \mathrm{m}_{1} / \Delta \mathrm{m}_{2}
$$

$\Delta \mathrm{m}_{1}$, mass loss of the sample without film. $\Delta \mathrm{m}_{2}$, mass loss of the sample with film.

In this paper, the samples with and without film were kept in vacuum furnace at $600{ }^{\circ} \mathrm{C}$ for $10 \mathrm{~h}$, and the mass of the samples before and after the experiment was measured. The larger the PRF value was, the better the hydrogen permeation resistance was. 


\subsubsection{Vacuum Thermal Dehydrogenation}

The VTD method was employed to assess the hydrogen permeation resistance performance by pressure changes. The zirconium hydride samples with and without film were placed in a tubular furnace and vacuumed to $10^{-5} \mathrm{~Pa}$ first, and then the vacuum sample chamber was heated to $600{ }^{\circ} \mathrm{C}$ and kept for $10 \mathrm{~h}$, during which the pressure changes with time were recorded. At the same time and temperature, the lower the pressure was, the lower the hydrogen penetration rate was, and the better the performance of the film was in terms of the hydrogen permeation resistance.

\subsubsection{Hydrogen Permeation Rate}

In cooperation with China Institute of Atomic Energy, gas chromatography hydrogen permeability measuring equipment (GCHPME) was used to measure HPR, which consisted of sample bed, gas storage tank, vacuum system, circulating pump, pressure regulator and MicoGC3000 gas chromatograph (Shanghai, China), as shown in Figure 1. Zirconium hydride with different films were placed in GCHPME, and measured at $600^{\circ} \mathrm{C}$ with starting atmosphere of $\mathrm{He}+50 \% \mathrm{CO}_{2}$ for 7 days. Reactions that may occur during the measurement are as follows:

$$
\begin{gathered}
\mathrm{ZrH}_{\mathrm{x}}=\mathrm{Zr}+\mathrm{x} / 2 \mathrm{H}_{2}(\mathrm{~g}) \\
\mathrm{H}_{2}(\mathrm{~g})+\mathrm{CO}_{2}(\mathrm{~g})=\mathrm{CO}(\mathrm{g})+\mathrm{H}_{2} \mathrm{O}(\mathrm{g})
\end{gathered}
$$

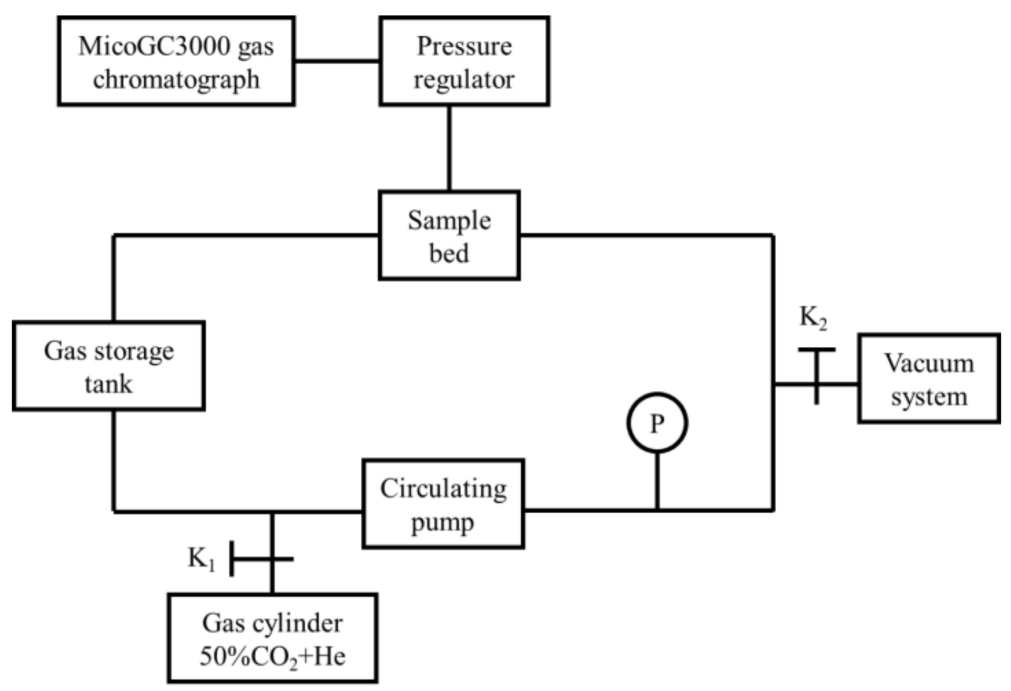

Figure 1. Schematic diagram of hydrogen permeation rate test equipment.

During the experiment, the content of $\mathrm{H}_{2}, \mathrm{CO}$, and $\mathrm{CO}_{2}$ in the system were measured by gas chromatography every day, and the content of $\mathrm{H}_{2}$ and $\mathrm{CO}$ were used to calculate the HPR. Details of the equipment and calculation model are presented by Qi et al. [22] and Bai et al. [27].

\section{Results and Discussion}

\subsection{Morphology}

Figure 2 shows the appearance of the zirconium hydride sample before and after the in situ reaction. The surface of the original zirconium hydride sample was gray with a metallic luster, and became golden after the in situ reaction. Niyomsoan et al. [28] showed that the color of the zirconium nitride varies with the nitrogen partial pressure, and the typical color of zirconium nitride was golden. It was inferred that the films containing zirconium nitride were grown on the surface after the in situ reaction of nitrogen with zirconium hydride. 


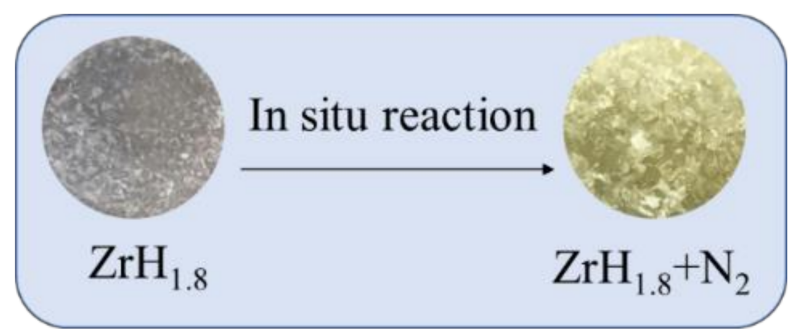

Figure 2. The appearance of the zirconium hydride sample before and after in situ reaction.

Figure 3 shows the results of SEM and EDS analysis of the films on zirconium hydride after the in situ reaction. Figure 3a showed the surface of the sample was smooth, continuous, and dense. The EDS result showed that there were $\mathrm{Zr}, \mathrm{N}$, and $\mathrm{O}$ on the surface of the sample, which indicated that zirconium nitride and zirconium oxide films were possibly formed. Figure $3 b$ showed cross-section morphology, in which it can be seen that the film was continuous and compact, tightly combined with the substrate, and the thickness was about $1.6 \mu \mathrm{m}$. $\mathrm{N}$ and $\mathrm{Zr}$ elements were detected in the cross-section regions 1 and 2 of the film with about 1:1 N/Zr atomic ratio, indicating that the film was possibly composed of $\mathrm{ZrN}$, and only $\mathrm{Zr}$ element was detected in the matrix region 3, corresponding to the $\mathrm{ZrHx}$ composition of the matrix.

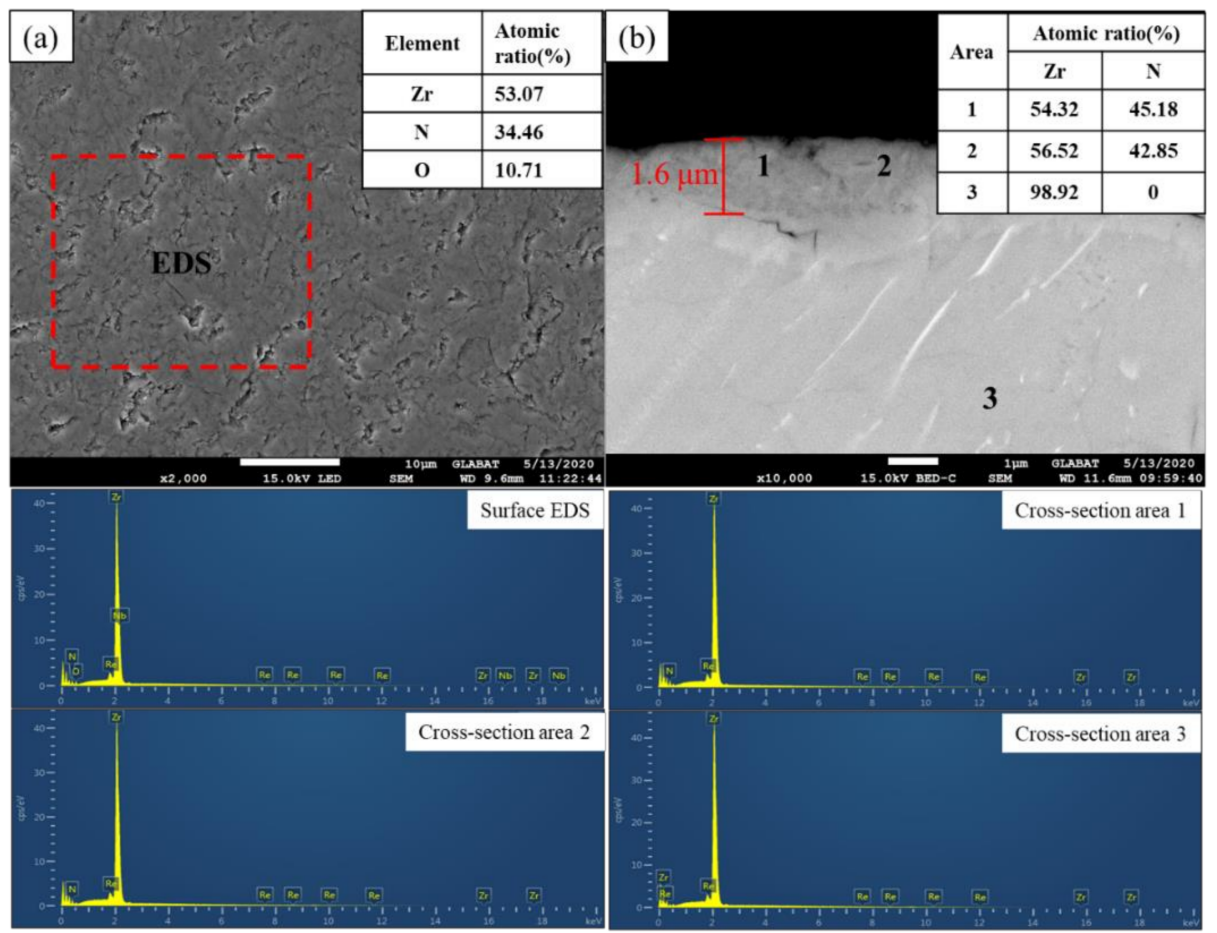

Figure 3. SEM images of the films: (a) surface morphology; (b) cross-section morphology.

\subsection{Phase Structure}

Figure 4 and Table 3 show the XRD patterns of the blank $\mathrm{ZrH}_{1.8}$, conventional XRD of the nitride film, and grazing incidence XRD (GIXRD) of nitride film. The phase of the blank $\mathrm{ZrH}_{1.8}$ was $\mathrm{ZrH}_{1.801}$; the phases of the films by conventional XRD analysis were $\mathrm{ZrH}_{1.801}$, $\mathrm{ZrN}, \mathrm{ZrO}$, and $\mathrm{ZrN}_{0.36} \mathrm{H}_{0.8}$; and the phases of the films by GIXRD analysis were $\mathrm{ZrH}, \mathrm{ZrN}$, $\mathrm{ZrO}_{2}$, and $\mathrm{ZrN}_{0.36} \mathrm{H}_{0.8}$. The existence of $\mathrm{ZrH}_{1.801}$ peak was caused by the $\mathrm{X}$-ray penetration through the thin film. The existence of $\mathrm{ZrN}, \mathrm{ZrO}_{\mathrm{x}}\left(\mathrm{x}=1\right.$ or 2), and $\mathrm{ZrN}_{0.36} \mathrm{H}_{0.8}$ phases in the conventional XRD and GIXRD analysis indicated that a composite film was formed on the surface of the zirconium hydride by in situ reaction of nitrogen with zirconium hydride, where the $\mathrm{O}$ may be originated from the zirconium hydride matrix, impurities 
of the nitrogen or introduced during sealing. It can be seen from the figure that the main peak is $\mathrm{ZrN}$. The detection of $\mathrm{ZrN}_{0.36} \mathrm{H}_{0.8}$ phase indicated that the nitrogen in the films may capture hydrogen penetrated from zirconium hydride matrix and form N-H bond, revealing the hydrogen barrier mechanism of nitride film.

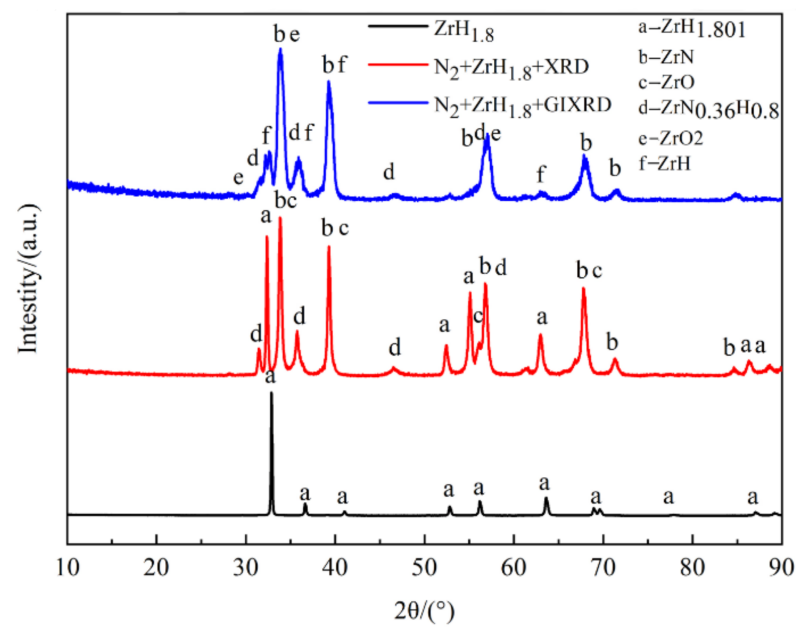

Figure 4. XRD spectrum of zirconium hydride before and after in situ reaction.

Table 3. XRD results before and after in-situ reaction of zirconium hydride in nitrogen atmosphere.

\begin{tabular}{ccccc}
\hline Sample & \multicolumn{3}{c}{ Phase } \\
\hline Blank $\mathrm{ZrH}_{1.8}$ & \multicolumn{3}{c}{$\mathrm{ZrH}_{1.801}$} \\
XRD of film & $\mathrm{ZrH}_{1.801}$ & $\mathrm{ZrN}$ & $\mathrm{ZrN}_{0.36} \mathrm{H}_{0.8}$ & $\mathrm{ZrO}$ \\
GIXRD of film & $\mathrm{ZrH}$ & $\mathrm{ZrN}$ & $\mathrm{ZrN}_{0.36} \mathrm{H}_{0.8}$ & $\mathrm{ZrO}_{2}$ \\
\hline
\end{tabular}

\subsection{Element Distribution}

Figure 5 displays the AES element distribution in the film with sputtering depth; Figure 5 a represents the nitride film prepared in this paper; Figure $5 \mathrm{~b}$ indicates the oxide film prepared by Yan et al. [21]. Figure 5a shows that the main elements of the nitride film were $\mathrm{N}$ and $\mathrm{Zr}$, and the oxygen in the film might be derived from the impurities of the nitrogen and the affinity of oxygen with $\mathrm{Zr}$, and the existence of $C$ was caused by the contamination of the sample. With the increase of the sputtering depth, the content of $\mathrm{Zr}$ increased; while the content of $\mathrm{N}$ increased first but then decreased, with the highest $\mathrm{N}$ content of about $65 \%$ at a depth of $500 \mathrm{~nm}$. The content of $\mathrm{O}$ decreased to zero when the sputtering depth was greater than $350 \mathrm{~nm}$. Thus, it can be concluded that the diffusion depth of nitrogen was deeper than that of oxygen, which might be due to the fact that the in situ reaction was carried out in nitrogen atmosphere. The content of $\mathrm{Zr}$ and $\mathrm{N}$ were equal at the depth of $2160 \mathrm{~nm}$, corresponding to the composition of $\mathrm{ZrN}$ that was detected by XRD analysis; and the elements composition in the film by AES analysis were coherent with the SEM and XRD results.

The composition of the film of this study was compared with that of the previously studied sample that was formed by the in situ reaction with urea at $600{ }^{\circ} \mathrm{C}$, as shown in Figure $5 b$ [21]. Both the films were composed of $C, N, O$, and $\mathrm{Zr}$; however, $\mathrm{N}$ was the main interstitial element in the film of this study, and $\mathrm{O}$ was the main interstitial element in the film of the previous study, and the content of $C$ in the film of this study is obviously lower than that of the previous study with urea as the reaction material. The reason for the composition difference between these two kinds of films was that the nitride film of this study was prepared in nitrogen atmosphere with residual content of oxygen at $800{ }^{\circ} \mathrm{C}$, whereas the film of the previous study was prepared through the pyrolysis of urea at $600{ }^{\circ} \mathrm{C}$ which provided relatively more $\mathrm{O}$ and $\mathrm{C}$ and less $\mathrm{N}$. In addition, the higher temperature provided a better diffusion condition for $\mathrm{N}$ in the film in this study. 

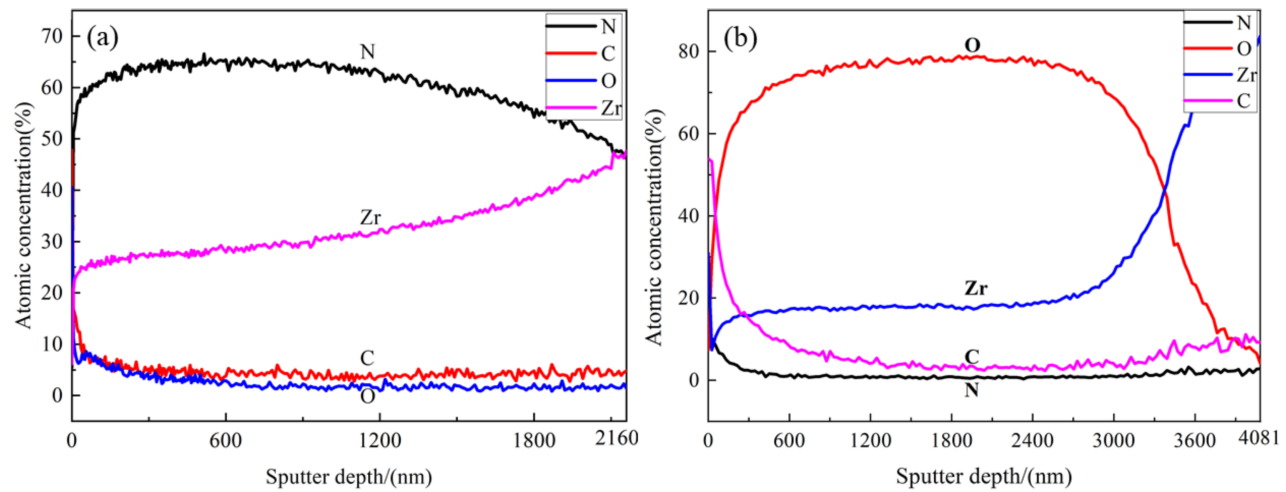

Figure 5. AES element distribution in the film with sputtering depth: (a) nitride film prepared in this paper; (b) oxide film prepared by Yan et al. [21].

\subsection{Valence State}

XPS was used to analyze the elements content and their valence state in the film. XPS sputtering depth of $0-1000 \mathrm{~nm}$ was selected in the analysis. Figure 6 shows the full XPS spectrum of nitride film at different sputtering depth. The peak of $C$ gradually disappeared with the increase of sputtering depth. The peaks of $\mathrm{Zr}$ and $\mathrm{N}$ intensified with the increase of the sputtering depth when the sputtering depth was less than $200 \mathrm{~nm}$. However, the peaks of $\mathrm{Zr}$ and $\mathrm{N}$ showed no obvious change in the sputtering depth from $400 \mathrm{~nm}$ to $1000 \mathrm{~nm}$, which was consistent with the results of the AES in Figure 5. In addition, the peak of $\mathrm{O}$ showed little change with sputtering depth from $30 \mathrm{~nm}$ to $1000 \mathrm{~nm}$.

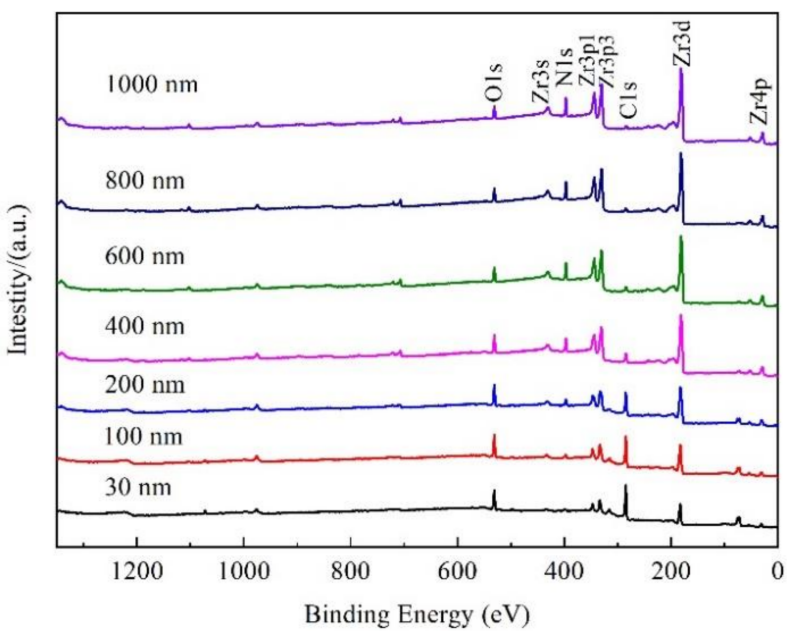

Figure 6. Full XPS spectrum of nitride film with sputtering depths.

The element content at different depths of the film was calculated from the XPS peak area. Figure 7 shows the atomic concentration of $\mathrm{Zr}, \mathrm{C}, \mathrm{N}$, and $\mathrm{O}$ in the film at different sputtering depths. With the increase of the sputtering depth, the content of $\mathrm{Zr}$ and $\mathrm{N}$ increased, while those of $\mathrm{C}$ and $\mathrm{O}$ decreased, which was consistent with the results of the AES result in Figure 5a. The content of $C$ was zero when the sputtering depth exceeded $400 \mathrm{~nm}$. The content of $\mathrm{N}$ was lower than that of O in XPS analysis in Figure 7, whereas the content of $\mathrm{N}$ was higher than that of $\mathrm{O}$ in AES analysis in Figure 5a, owing to the different analysis methods. Through literature [12,20,29] and consultation with XPS analysis specialist, the XPS was mainly used to determine the valence state of elements qualitatively, the content analysis was semi quantitative and less applied, and the quantitative analysis result of XPS was not as reliable as that of AES. 


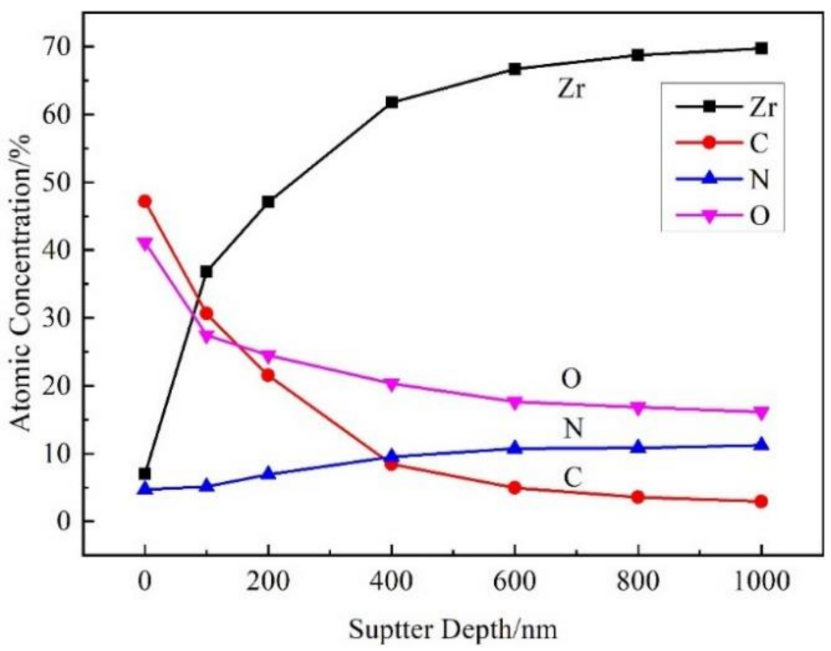

Figure 7. The element distribution of nitride film with different sputtering depths.

The XPS narrow-spectrum analysis was measured at $30 \mathrm{~nm}, 200 \mathrm{~nm}, 600 \mathrm{~nm}$, and $1000 \mathrm{~nm}$, respectively, and the binding energy of C1s $(284.8 \mathrm{eV})$ was used to calibrate the XPS peaks. Figure 8 showed the XPS narrow spectrum of C1s, Zr3d, O1s, and N1s at different sputtering depths, and the peak values were fitted in Table 4. C1s was all decomposed into two peaks at different depths, and the peak at $284.8 \mathrm{eV}$ was $\mathrm{C}-\mathrm{C}$, and at $282.1 \mathrm{eV}$ was assigned to $\mathrm{ZrC}$, and the peak at $286 \mathrm{eV}$ might refer to $\mathrm{C}-\mathrm{O}$ [30]. There were four peaks at each depth after fitting the peak of $\mathrm{Zr3d}$, implying that the films were zirconia and zirconium nitride, and the peaks of zirconium nitride increased with the increase of the sputtering depth, which was consistent with the AES results in Figure 5. There were two peaks at each depth after fitting the peak of O1s, the first peak corresponded to $\mathrm{ZrO}_{2}$ at different depths, and the second peak referred to $\mathrm{O}-\mathrm{H}$ bond [21,31]. The peak of N1s was similarly consulted [32], and the results showed that nitrogen in the film was in the form of $\mathrm{N}-\mathrm{H}$ and $\mathrm{ZrN}$. The formation of $\mathrm{O}-\mathrm{H}$ and $\mathrm{N}-\mathrm{H}$ bonds in the film indicated that the oxygen and nitrogen captured the hydrogen from the zirconium hydride, and revealed the mechanism of hydrogen permeation. Compared with XPS, electron energy loss spectroscopy (EELS) can also be used for element content and valence analysis with higher resolution and accuracy; local chemical variations of $\mathrm{H}$ were recently measured by it $[33,34]$, and will be used in the study of films prepared on zirconium hydride later.

Table 4. Binding energy values of XPS narrow spectrum of the nitride film.

\begin{tabular}{cccccc}
\hline Elements & h/nm & Peak1/eV & Peak2/eV & Peak3/eV & Peak4/eV \\
\hline \multirow{3}{*}{ C1s } & 30 & 284.78 & 285.67 & - & - \\
& 200 & 284.80 & 285.42 & - & - \\
& 600 & 284.82 & 282.12 & - & - \\
& 1000 & 284.82 & 282.17 & - & 185.36 \\
Zr3d & 30 & 179.84 & 182.70 & 184.85 & 185.52 \\
& 200 & 179.94 & 180.27 & 182.89 & 184.84 \\
& 600 & 179.55 & 179.92 & 182.24 & - \\
O1s & 1000 & 179.77 & 181.14 & 182.23 & - \\
& 30 & 530.71 & 531.83 & - & - \\
& 200 & 531.24 & 532.64 & - & - \\
N1s & 600 & 530.82 & 532.32 & - & - \\
& 1000 & 530.84 & 532.09 & 534.66 & - \\
& 30 & 398.67 & - & - & - \\
\hline
\end{tabular}



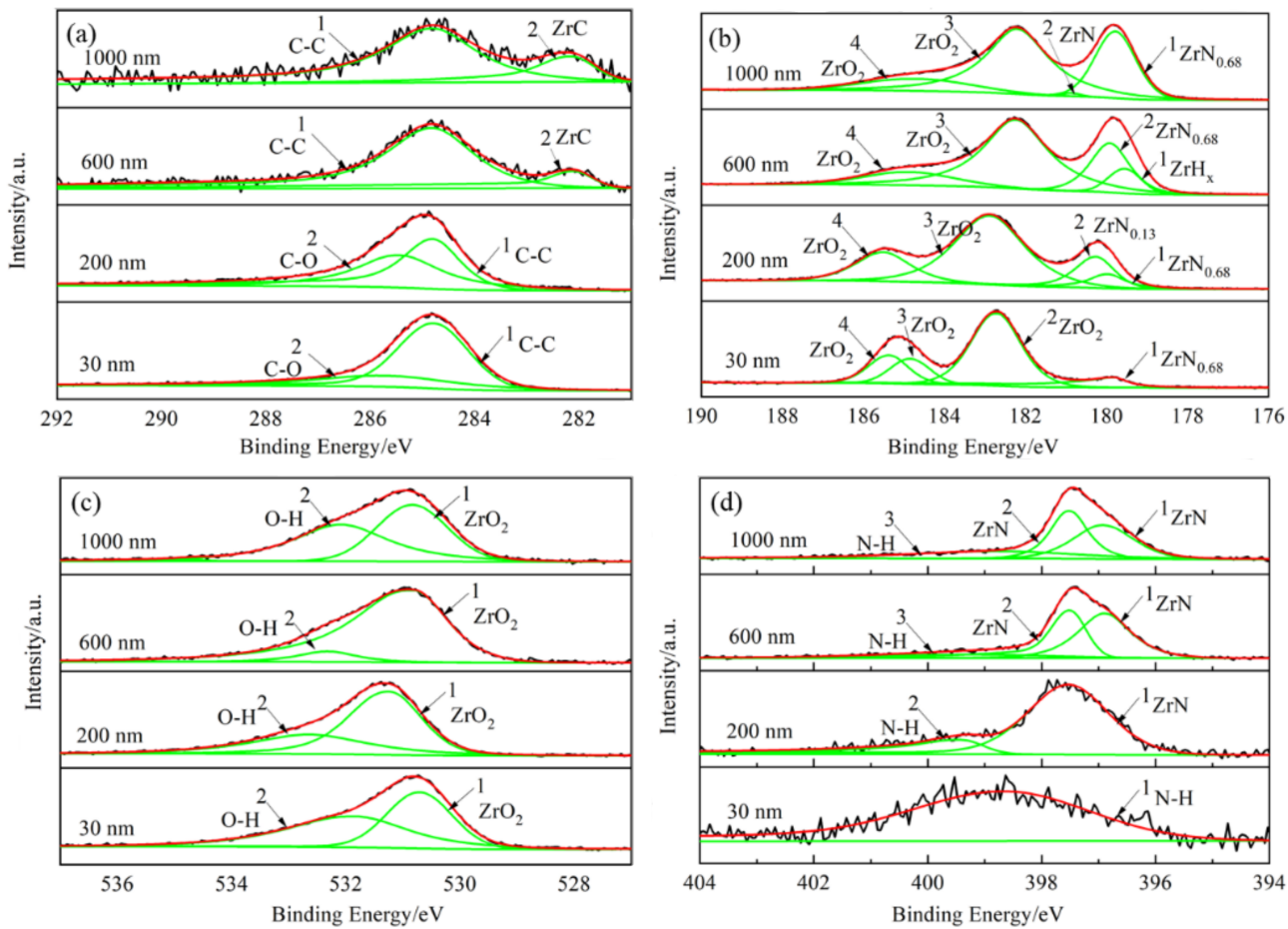

Figure 8. XPS narrow spectrum of $\mathrm{C} 1 \mathrm{~s}, \mathrm{Zr} 3 \mathrm{~d}, \mathrm{O} 1 \mathrm{~s}$, and N1s at different sputtering depths. (a) C1s; (b) Zr3d; (c) O1s; (d) N1s.

\subsection{Hydrogen Permeation Behavior}

The hydrogen permeation resistance performance of nitride film was studied by three different methods including (1) PRF; (2) VTD; (3) HPR, and the results were compared with oxide film prepared by in situ reaction with $\mathrm{CO}_{2}[18]$.

\subsubsection{Permeation Reduction Factor}

PRF measurement results of zirconium hydride samples with two different films (nitride and oxide films) are given in Table 5. The PRF values of the oxide and nitride films were 3.48 and 9.40 respectively, indicating that the hydrogen permeation resistance effect of nitride film was better than that of oxide film. The PRF value of zirconium hydride with nitride and oxide films was lower than stainless steel with films [9-17], which is because zirconium hydride is a brittle compound and surface defects are inevitable, and the quality of film on zirconium hydride must be much inferior than that on stainless steel.

Table 5. PRF values of zirconium hydride samples with different films.

\begin{tabular}{cccccccc}
\hline Samples & $\mathbf{m}_{\mathbf{1}} \mathbf{g}$ & $\mathbf{m}_{\mathbf{2}} / \mathbf{g}$ & $\mathbf{\Delta} \mathbf{m} / \mathbf{g}$ & $\Delta \mathbf{m} / \mathbf{S} \mathbf{g} \cdot \mathbf{m}^{-2}$ & PRF & $\begin{array}{c}\text { Average } \\
\text { PRF }\end{array}$ & $\begin{array}{c}\text { Standard } \\
\text { Deviation }\end{array}$ \\
\hline \multirow{2}{*}{$\mathrm{ZrH}_{1.8}$} & 5.833 & 5.825 & 0.008 & & & & - \\
& 20.0762 & 20.0625 & 0.0137 & 3.7230 & - & & \\
Oxide film & 20.0358 & 20.0195 & 0.0163 & & & & \\
& 5.4483 & 5.4447 & 0.0036 & 1.1983 & 3.1069 & & \\
& 19.7596 & 19.7555 & 0.0041 & 1.1770 & 3.1631 & 3.4811 & \\
Nitride film & 19.6229 & 19.6198 & 0.0031 & 0.8921 & 4.1733 & & \\
& 5.3744 & 5.3735 & 0.0009 & 0.2962 & 12.5692 & & \\
& 19.1102 & 19.1087 & 0.0015 & 0.4372 & 8.5156 & 9.3970 & 2.3157 \\
\hline
\end{tabular}




\subsubsection{Vacuum Thermal Dehydrogenation}

The pressure changes with treatment time for bare $\mathrm{ZrH}_{1.8}, \mathrm{ZrH}_{1.8}$ with oxide film, and $\mathrm{ZrH}_{1.8}$ with nitride film are shown in Figure $9(\mathrm{a}-\mathrm{c})$ respectively, and the temperature change with treatment time is shown in Figure 9(d) in the vacuum thermal dehydrogenation experiments. It can be seen that when the temperature was lower than $470{ }^{\circ} \mathrm{C}$, the pressure of the three different samples did not change during heat treatment, indicating that the dehydrogenation temperature of zirconium hydride was higher than $470{ }^{\circ} \mathrm{C}$. With the increase in temperature from $470{ }^{\circ} \mathrm{C}$ to $600{ }^{\circ} \mathrm{C}$ and during the $10 \mathrm{~h}$ holding period at $600{ }^{\circ} \mathrm{C}$, the pressure of the three different samples increased continuously, indicating that gas emission occurred. The pressure value from high to low of the three kinds of samples showed an order of bare $\mathrm{ZrH}_{1.8}>\mathrm{ZrH}_{1.8}$ with oxide film $>\mathrm{ZrH}_{1.8}$ with nitride film. Under vacuum condition, the pressure represented the amount of hydrogen loss, and the greater the pressure was, the more the hydrogen loss was. Therefore, the hydrogen permeation resistance effect of nitride film was better than that of oxide film, which was consistent with the PRF value results.

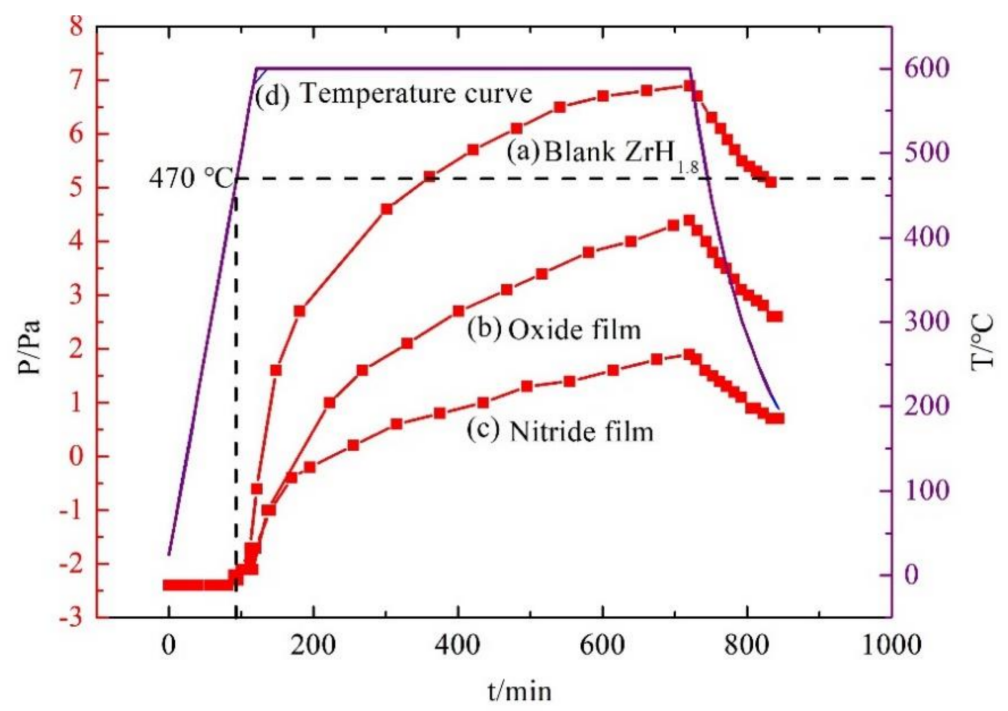

Figure 9. t-T-P curves of different films by vacuum thermal dehydrogenation: (a) Blank $\mathrm{ZrH}_{1.8}$; (b) Oxide film; (c) Nitride film; (d) Temperature curve.

\subsubsection{Hydrogen Permeation Rate}

The zirconium hydride samples with nitride film and oxide film were tested in $\mathrm{He}+50 \% \mathrm{CO}_{2}$ atmosphere at $600{ }^{\circ} \mathrm{C}$, and the content changes of $\mathrm{H}_{2}, \mathrm{CO}$, and $\mathrm{CO}_{2}$ with treatment time are shown in Figure 10. It could be seen that the contents of $\mathrm{H}_{2}, \mathrm{CO}$, and $\mathrm{CO}_{2}$ for zirconium hydride samples with two different films had the same variation trend with the increase of treatment time. The $\mathrm{CO}_{2}$ content kept decreasing with treatment time; the contents of $\mathrm{CO}$ and $\mathrm{H}_{2}$ increased with the treatment time, but these contents in the sample with the oxide film were obviously higher than that of the nitride film, indicating that the nitride film had better hydrogen permeation resistance effect.

Based on the measured contents of $\mathrm{CO}$ and $\mathrm{H}_{2}$ calculated by the model developed by Qi et al. [22] and Bai et al. [27], the hydrogen permeation rate $\mathrm{Va}\left(\mathrm{kg} \cdot \mathrm{m}^{-2} \cdot \mathrm{s}^{-1}\right)$ was calculated and is listed in Table 6.

Figure 11 shows the fitting results of hydrogen permeation rates of the two films, and the results demonstrate that the relationship between hydrogen permeation rate Va $\left(\mathrm{kg} \cdot \mathrm{m}^{-2} \cdot \mathrm{s}^{-1}\right)$ and time $\mathrm{t}(\mathrm{s})$ for nitride film and oxide film conformed to Equations (4) and (5), respectively:

$$
\begin{aligned}
& \mathrm{V}_{\mathrm{a}}=0.00309 \times(\mathrm{t}+1059)^{-1.236} \\
& \mathrm{~V}_{\mathrm{a}}=0.00404 \times(\mathrm{t}+2191)^{-1.175}
\end{aligned}
$$



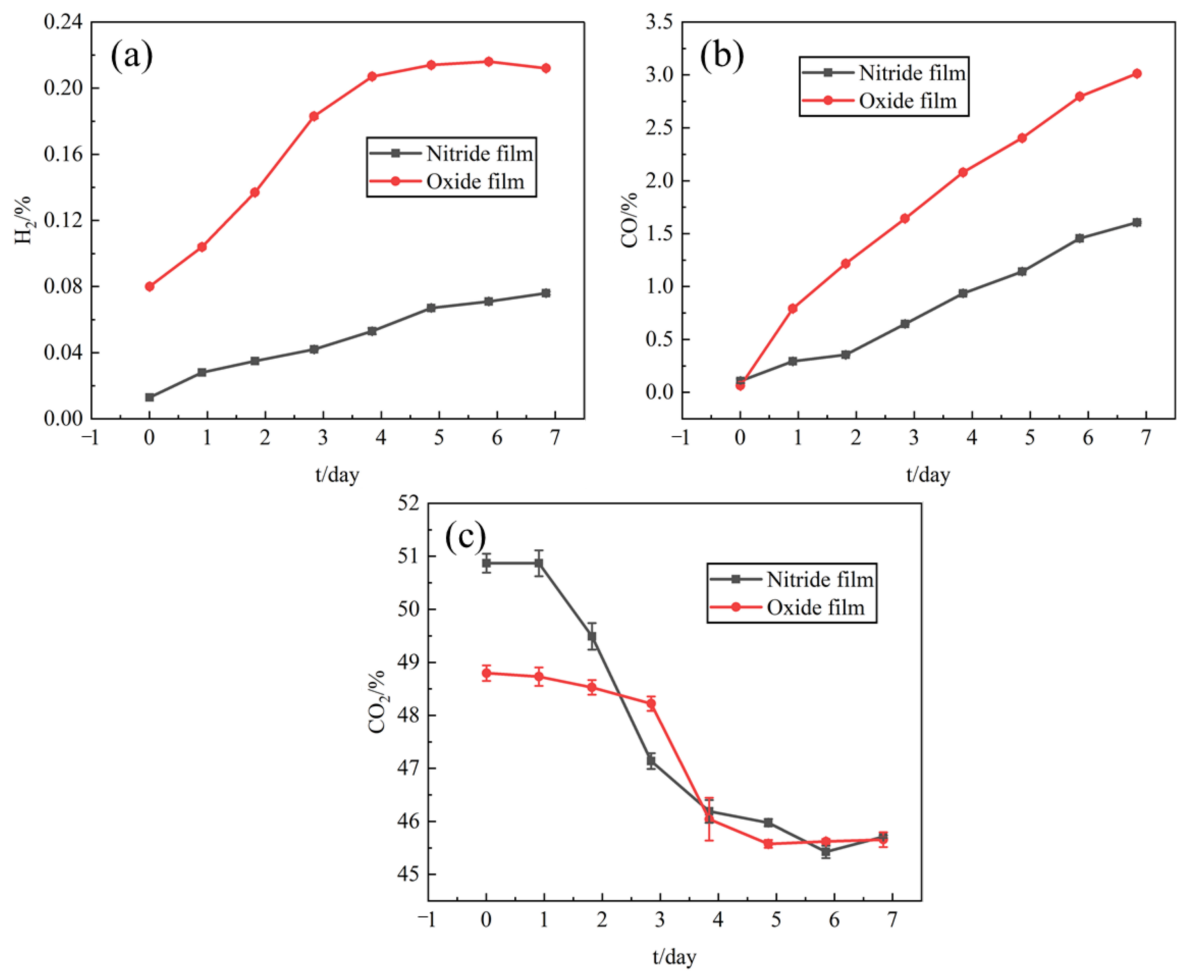

Figure 10. Variation of $\mathrm{H}_{2}, \mathrm{CO}$, and $\mathrm{CO}_{2}$ content with time of different films. (a) $\mathrm{H}_{2} ;$ (b) $\mathrm{CO}$; (c) $\mathrm{CO}_{2}$.

Table 6. Hydrogen permeation rate of different films.

\begin{tabular}{|c|c|c|c|c|c|}
\hline \multicolumn{3}{|c|}{ Nitride Film } & \multicolumn{3}{|c|}{ Oxide Film } \\
\hline t/day & $\mathrm{Va} / \mathrm{kg} \cdot \mathrm{m}^{-2} \cdot \mathrm{s}^{-1}$ & $\sigma_{1}$ & t/day & $\mathrm{Va} / \mathrm{kg} \cdot \mathrm{m}^{-2} \cdot \mathrm{s}^{-1}$ & $\sigma_{2}$ \\
\hline 0.003 & $4.309 \times 10^{-7}$ & $1.67867 \times 10^{-8}$ & 0.003 & $4.220 \times 10^{-7}$ & $2.78229 \times 10^{-9}$ \\
\hline 0.907 & $2.364 \times 10^{-9}$ & $2.82329 \times 10^{-11}$ & 0.625 & $1.072 \times 10^{-8}$ & $2.09711 \times 10^{-10}$ \\
\hline 1.820 & $5.344 \times 10^{-10}$ & $3.29286 \times 10^{-11}$ & 1.509 & $3.424 \times 10^{-9}$ & $1.38303 \times 10^{-10}$ \\
\hline 2.841 & $1.596 \times 10^{-9}$ & $2.22545 \times 10^{-11}$ & 2.575 & $2.167 \times 10^{-9}$ & $6.02349 \times 10^{-11}$ \\
\hline 3.843 & $1.354 \times 10^{-9}$ & $7.21309 \times 10^{-11}$ & 3.707 & $1.608 \times 10^{-9}$ & $1.38992 \times 10^{-11}$ \\
\hline 4.862 & $8.778 \times 10^{-10}$ & $3.29768 \times 10^{-11}$ & 4.598 & $1.265 \times 10^{-9}$ & $4.48827 \times 10^{-11}$ \\
\hline 5.855 & $1.201 \times 10^{-9}$ & $9.16133 \times 10^{-12}$ & 5.640 & $1.260 \times 10^{-9}$ & $1.38900 \times 10^{-11}$ \\
\hline 6.843 & $5.707 \times 10^{-10}$ & $3.71908 \times 10^{-11}$ & 6.470 & $6.866 \times 10^{-10}$ & $4.30914 \times 10^{-11}$ \\
\hline
\end{tabular}

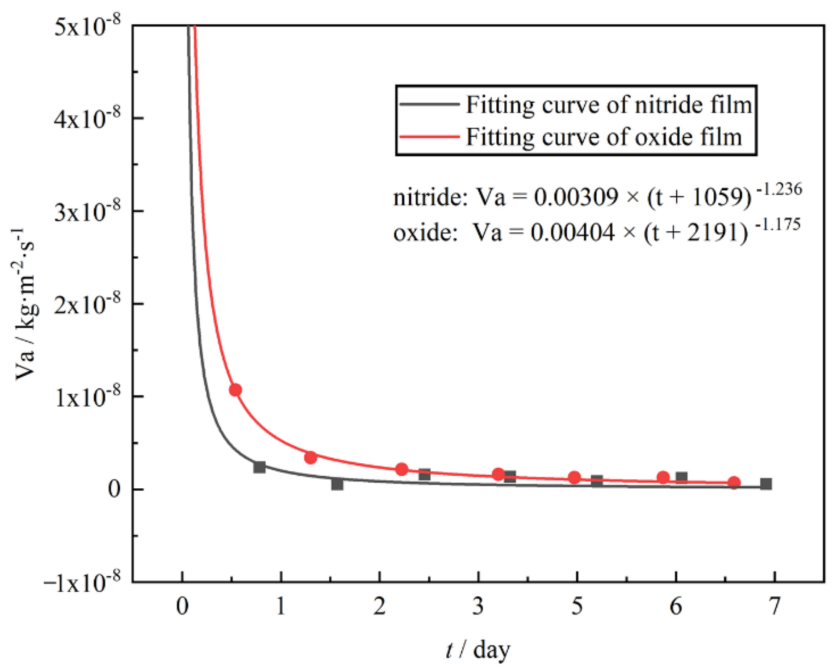

Figure 11. Fitting diagram of hydrogen permeation rate of different films. 
According to Equations (4) and (5), the hydrogen loss over a long period of time was predicted and listed in Table 7 . It can be found that the hydrogen loss value of nitride film was $3.179 \%, 3.228 \%$, and $3.254 \%$, while that of oxide film was $7.069 \%, 7.259 \%$, and $7.360 \%$ for 1, 2, and 3 years, respectively. The predicted hydrogen loss values of oxide film were higher than that of nitride film, indicating that the nitride film exhibited better hydrogen permeation resistance effect than the oxide film. This result supported the results of PRF and VTD methods.

Table 7. Fitting formula of different films and prediction of hydrogen loss in 1-3 years.

\begin{tabular}{ccccc}
\hline Film & $\mathbf{V a} / \mathbf{k g} \cdot \mathbf{m}^{-\mathbf{2}} \cdot \mathbf{s}^{-\mathbf{1}}$ & $\mathbf{R}^{\mathbf{2}}$ & $\mathbf{1}$ Year & 2 Year \\
\hline Nitride & $\mathrm{V}_{\mathrm{a}}=0.00309 \times(\mathrm{t}+1059)^{-1.236}$ & 0.99998 & $3.179 \%$ & $3.228 \%$ \\
Oxide & $\mathrm{V}_{\mathrm{a}}=0.00404 \times(\mathrm{t}+2191)^{-1.175}$ & 1 & $7.069 \%$ & $7.259 \%$ \\
\hline
\end{tabular}

\section{Conclusions}

In this work, a composite nitride film was prepared on zirconium hydride by the in situ reaction method in a nitrogen atmosphere.

The film was golden color, smooth, continuous, and dense, with a thickness of about $1.6 \mu \mathrm{m}$. XRD analysis showed that the main phase of the film was $\mathrm{ZrN}$, with coexistence of $\mathrm{ZrO}_{2}, \mathrm{ZrO}$, and $\mathrm{ZrN}_{0.36} \mathrm{H}_{0.8}$. The element distribution of nitride film was compared with that of previously studied by in situ reaction with urea at $600{ }^{\circ} \mathrm{C}$ by $\mathrm{AES}$ analysis. Two types of films were composed of elements $\mathrm{C}, \mathrm{N}, \mathrm{O}$, and $\mathrm{Zr}$; the content of $\mathrm{N}$ in the film of this study was the main interstitial element, but $\mathrm{O}$ was the main interstitial element in the film of the previous study, and the content of $C$ in the film of this study was obviously lower than that of the previously studied with urea as the reaction material. XPS analysis revealed that there were $\mathrm{Zr}-\mathrm{C}, \mathrm{Zr}-\mathrm{O}, \mathrm{Zr}-\mathrm{N}, \mathrm{O}-\mathrm{H}, \mathrm{N}-\mathrm{H}$ bonds in the film, which further verified the results of AES analysis. Based on these characterization results, the hydrogen barrier mechanism could be attributed to the existence of the $\mathrm{ZrN}_{0.36} \mathrm{H}_{0.8}$ phase and the bonds of $\mathrm{O}-\mathrm{H}$ and $\mathrm{N}-\mathrm{H}$, indicating that the nitrogen and oxygen in the film could capture the hydrogen from zirconium hydride matrix.

Finally, the hydrogen permeation resistance performance of the nitride film was compared with that of oxide film by PRF, VTD, and HPR methods, and the results showed that the hydrogen permeation barrier effects of nitride film was better than that of oxide film. This study investigated the preparation and hydrogen permeation behavior of zirconium nitride film on zirconium hydride and revealed the hydrogen barrier mechanism of nitride films.

Author Contributions: Conceptualization, W.W. and G.Y.; methodology, L.W. and G.Y.; software, Z.M.; formal analysis, J.Z. and Z.M.; data curation, W.W., Z.G., S.Z. and Y.W.; writing-original draft preparation, W.W.; writing-review and editing, W.W. and L.W.; supervision, L.W., Z.G., S.Z., Y.W. and J.Z.; project administration, L.W.; funding acquisition, L.W. All authors have read and agreed to the published version of the manuscript.

Funding: This research was funded by National Natural Science Foundation of China (No. 51674035) and Youth Fund of General Research Institute for Nonferrous Metal (No. G12620203129016).

Institutional Review Board Statement: Not applicable.

Informed Consent Statement: Not applicable.

Data Availability Statement: The data presented in this study are available upon request from the corresponding author.

Acknowledgments: The authors gratefully acknowledge China Institute of Atomic Energy for their support with gas chromatography hydrogen permeability measuring equipment (GCHPME).

Conflicts of Interest: The authors declare no conflict of interest. 


\section{References}

1. Murakami, T. A historical review and analysis on the selection of nuclear reactor types and implications to development programs for advanced reactors; A Japanese study. Energy Rep. 2021, 7, 3428-3436. [CrossRef]

2. Yang, Q.F.; Lu, H.L. Research and application of space nuclear reactor power supply. Spacecraft Eng. 1995, 4, 11-21.

3. Bennett, G.L. A look at the Soviet space nuclear power program. In Proceedings of the 24th Intersociety Energy Conversion Engineering Conference, Washington, DC, USA, 6-11 August 1989; pp. 1187-1194.

4. Chernikov, A.S.; Syasin, V.A.; Kostin, V.M.; Boiko, E.B. Influence of hydrogen content on the strength and the presence of defects in zirconium hydride. J. Alloys Compd. 2002, 330-332, 393-395. [CrossRef]

5. Konashi, K.; Ikeshoji, T.; Kawazoe, Y.; Matsui, H. A molecular dynamics study of thermal conductivity of zirconium hydride. J. Alloys Compd. 2003, 356-357, 279-282. [CrossRef]

6. Tsuchiya, B.; Teshigawara, M.; Konashi, K.; Yamawaki, M. Thermal diffusivity and electrical resistivity of zirconium hydride. J. Alloys Compd. 2002, 330, 357-360. [CrossRef]

7. Tsuchiya, B.; Huang, J.; Konashi, K.; Teshigawara, K.; Yamawaki, M. Thermophysical properties of zirconium hydride and uranium-zirconium hydride. J. Nucl. Mater. 2001, 289, 329-333. [CrossRef]

8. Ma, M.W.; Liang, L.; Tang, B.H.; Xiang, W.; Wang, Y.; Cheng, Y.L.; Tan, X.H. Decomposition kinetics study of zirconium hydride by interrupted thermal desorption spectroscopy. J. Alloys Compd. 2015, 645, 217-220. [CrossRef]

9. Li, Q.; Liu, J.; Lv, W.L.; Mo, L.B.; Duan, D.W.; Gu, H.W.; Ding, F.Z.; Tang, T.; Luo, D.L.; Cao, J.L. Stability of $\mathrm{Y}_{2} \mathrm{O}_{3}$ hydrogen isotope permeation barriers in hydrogen at high temperatures. Int. J. Hydrog. Energy 2013, 38, 4266-4271. [CrossRef]

10. He, D.; Li, S.; Liu, X.P.; Zhang, C.; Yu, Q.H.; Wang, S.M.; Jiang, L.J. Preparation of $\mathrm{Cr}_{2} \mathrm{O}_{3}$ film by MOCVD as hydrogen permeation barrier. Fusion Eng. Des. 2014, 89, 35-39. [CrossRef]

11. Li, Q.; Wang, J.; Xiang, Q.Y.; Yan, K.; Yao, W.Q.; Cao, J.L. Study on influence factors of permeation reduction factor of $\mathrm{Al}_{2} \mathrm{O}_{3}$ hydrogen isotopes permeation barriers. Int. J. Hydrog. Energy 2016, 41, 4326-4331. [CrossRef]

12. Wu, Y.P.; Zhu, S.F.; Zhang, Y.P.; Liu, T.W.; Rao, Y.C.; Luo, L.Z.; Wang, Q.G. The adhesion strength and deuterium permeation property of $\mathrm{SiC}$ films synthesized by magnetron sputtering. Int. J. Hydrog. Energy 2016, 41, 10827-10832. [CrossRef]

13. Wang, J.; Li, Q.; Xiang, Q.Y.; Cao, J.L. Performances of AlN coatings as hydrogen isotopes permeation barriers. Fusion Eng. Des. 2016, 102, 94-98. [CrossRef]

14. Nemanič, V.; McGuiness, P.; Daneu, N.; Zajec, B.; Siketić, Z.; Waldhauser, W. Hydrogen permeation through silicon nitride films. J. Alloys Compd. 2012, 539, 184-189. [CrossRef]

15. Tamura, M.; Noma, M.; Yamashita, M. Characteristic change of hydrogen permeation in stainless steel plate by BN coating. Surf. Coat. Technol. 2014, 260, 148-154. [CrossRef]

16. Bazzanella, N.; Checchetto, R.; Miotello, A.; Patton, B.; Kale, A.N.; Kothari, D.C. High temperature efficient deuterium permeation and oxidation (Al,Ti)N barriers deposited on stainless steel. Appl. Phys. Lett. 2002, 81, 3762-3764. [CrossRef]

17. Mcguiness, P.J.; Čekada, M.; Nemanič, V.; Zajec, B.; Recnik, A. Hydrogen permeation through TiAlN-coated Eurofer ' 97 steel. Surf. Coat. Technol. 2011, 205, 2709-2713. [CrossRef]

18. Chen, W.D.; Wang, L.J.; Wang, J.W.; Yan, S.F. Oxidation behavior of zirconium hydride in $\mathrm{O}_{2}$ and $\mathrm{CO}_{2}$. Rare Met. Mater. Eng. 2008, 37, 1970-1972.

19. Wu, M.; Chen, Y.; Peng, J.Q.; Yan, G.Q.; Sun, Y.P.; Zhang, J.D.; Zhang, S.L.; Wang, L.J. Hydrogen permeation resistance and characterization of Si-Al and Si-Zr composite sol oxide coating on surface of zirconium hydride. Rare Met. 2017, 36, 55-60. [CrossRef]

20. Wu, M.; Peng, J.Q.; Yan, G.Q.; Chen, Y.; He, Z.Y.; Xu, Z.G.; Wang, L.J. Preparation and properties of composite hydrogen permeation barrier on $\mathrm{ZrH}_{1.8}$ by sol-gel technique. Surf. Coat. Technol. 2018, 352, 159-165. [CrossRef]

21. Yan, G.Q.; Chen, Y.; Wu, M.; Peng, J.Q.; Wang, L.J. AES/XPS analysis of in-situ reaction layer between urea and zirconium hydride at high temperature. Rare Met. Mater. Eng. 2016, 45, 3302-3305.

22. Qi, S.; Ma, Z.H.; Yan, G.Q.; Wang, Z.H.; Wang, L.J. Hydrogen permeation rate of coating zirconium hydride moderator-a prediction model. Int. J. Hydrog. Energy 2021, 45, 14710-14719. [CrossRef]

23. Zhou, D.P.; Peng, H.; Zhu, L.; Guo, H.B.; Gong, S.K. Microstructure, hardness and corrosion behaviour of Ti/TiN multilayer coatings produced by plasma activated EB-PVD. Surf. Coat. Technol. 2014, 258, 102-107. [CrossRef]

24. Cui, Z.Q.; Qin, Y.C. Metallurgy and Heat Treatment; China Machine Press: Beijing, China, 2007; pp. $299-302$.

25. Zhang, H.; Qin, H.F.; Ren, Z.C.; Zhao, J.Y.; Hou, X.N.; Doll, G.L.; Donga, Y.L.; Ye, C. Low-temperature nitriding of nanocrystalline Inconel 718 alloy. Surf. Coat. Technol. 2017, 330, 10-16. [CrossRef]

26. Yilbas, B.S.; Ali, H.; Karatas, C.; Al-Sharafi, A. Laser gas assisted nitriding and characterization of tungsten surface. Opt. Laser Technol. 2018, 107, 274-280. [CrossRef]

27. Bai, S.; Yuan, X.M.; Yan, G.Q.; Liu, Z.X.; Yang, H.Q.; Wang, L.J. Hydrogen permeation rate and stability of in-situ oxide layer on surface of $\mathrm{ZrH}_{1.85}$ at $600{ }^{\circ} \mathrm{C}$. Rare Met. 2020, 44, 41-47.

28. Niyomsoan, S.; Grant, W.; Olson, D.L.; Mishral, B. Variation of color in titanium and zirconium nitride decorative thin films. Thin Solid Film. 2002, 415, 187-194. [CrossRef]

29. Xin, Z.Y.; Yin, X.R.; Ling, Y.H.; Zhang, Z.J.; Liu, X.; Liang, H.; Deng, X.K. Hydrogen permeation behavior and mechanism of $\mathrm{Cr}_{2} \mathrm{O}_{3} / \mathrm{Al}_{2} \mathrm{O}_{3}$ bipolar oxide film under plasma discharging environment. Int. J. Hydrog. Energy. 2017, 42, 20869-20878. [CrossRef]

30. Shchukarev, A.V.; Korolkov, D.V. XPS Study of group IA carbonates. Cent. Eur. J. Chem. 2004, 2, 347-362. [CrossRef] 
31. Liu, Q.S.; Qin, L.J.; Chang, Y.; Zhao, P. Preparation of hydrogen permeation barrier layer on zirconium hydride surface by $\mathrm{CO}_{2}$ reaction method. Surf. Technol. 2005, 2, 32-34.

32. Muneshwar, T.; Cadien, K. Comparing XPS on bare and capped ZrN films grown by plasma enhanced ALD: Effect of ambient oxidation. Appl. Surf. Sci. 2018, 435, 367-376. [CrossRef]

33. Tunes, M.A.; Silva, C.M.; Edmondson, P.D. Site specific dependencies of hydrogen concentrations in zirconium hydrides. Scr. Mater. 2019, 158, 136-140. [CrossRef]

34. Woo, O.T.; Carpenter, G.J.C. EELS characterization of zirconium hydrides. Microsc. Microanal. Microstruct. 1992, 3, 35-44. 